\title{
الرشاقة الاستراتيجية للجامعات المصرية فى مواجهة جائحة كورونا (Covid-19)- ضرورة حتمية
}

\author{
إعـداد \\ أ.د. أشرف السعيد أحمد محمد إعد
}

أستاذ بقسم أصول التربية- كلية التربية - جامعة المنصورة

أحدثت جائحة فيروس كورونا أو (Covid-19) تحولات راديكالية فى مجريات الحياة البشرية فى معظم الدول، فلقد غيرت نمط الحياة والعمل، وفرضت التباعد الاجتماعي، وأوققت حركة التتقل والسفر بين الدول، وأصابت الاقتصادات العالمية بهزة عنيفة أعادت للأذهان شبح "الكساد العظيم" فى ثلاثثنيات القرن العشرين، وتزايدت معدلات البطالة حيث فقد الملايين وظائفهم حول العالم، وزادت معدلات الفقر ، وانكشفت الاختلالات الهيكلية فى القدرة على التكيف السريع مع تبعات هذه الجائحة فى الكثير من النظ الصحية والاقتصادية حول العالم.

ولم تكن النظم التعليمية بمنأى عن التأثيرات العاصفة لجائحة كورونا، بل توقفت على الفور كافة

مناثط التعليم والتعلم، وأغلقت المدارس والجامعات، وأضطرت بعض الدول إلى ترفيع طلابها إلى السنة التالية دون استكمال متطلبات عملية التعليم والتعلم، وحاولت بعض الدول ايجاد صيغ جديدة لاستكمال العام الدراسي، من خلال أنظمة التعليم عن بعد، والتعليم الاككتروني. لقد فرضت جائحة كورونـا ضرورة التغيير السريع والمدروس فى أنماط عمل النظم التعليمية، وأظهرت الحاجة إلى المرونة الاستراتيجية فى التعامل مع الظروف الطارئة وغير المتوقعة من خلال بناء أنظمة رشيقة قادرة على التكيف الذى يواجها التحديات بكفاءة وبستتمر الفرص أو بقتتصها باحترافية ويجعل المؤسسات التعليمية دائمـا على الطريق 
إنّ التغييرات المتسارعة فى المشهـ العـالمي عموما والتحولات الهيكليـة التى تصبي الكيانات المؤسسة العاملة فى مجال التعليم والتعلم فى عالم فيروس كورونا وما بعدها يقتضي اعادة بناء النظم المؤسسية بعناصرها الأساسية ورؤاهـا المستقلية وفقا لمفهوم الرشـاقة الاستراتيجية التى تعزز من قدرة المؤسسات والموارد البشرية العاملة فيها على المرونة فى مواجهة حالة عدم اليقين والغموض المتزايد، والتكيف المستمر للتغيرات الممكنـة والمحتملـة فى احتياجـات المستفيدين وطموحـاتهم، وعلى استـامة التتافسية من خلال الاحتفاظ بالفرص القائمة والتوجه الاستراتيجي لاقتتاص الفرص المحتملة. لقد خلقت الطبيعة المتغيرة للاقتصـاد العالمي بيئة من التعقيد المفرط والتغير الديناميكي غير المسبوق، لذلك قواعد اللعبة التنافسية تتغير بشكل أسرع من قدرة المديرين والقادة على التفاعل معها، وتبثر هذه الديناميات بموجـه مستمرة من التغيرات فى العمل ومصـادر القيمـة المضـافة ممـا، يفرض ضرورة تنبي نهج الرشاقة الاستراتيجية فى التعامل مع هذه الموجة المستمرة من التغيرات(Roth, 1996)

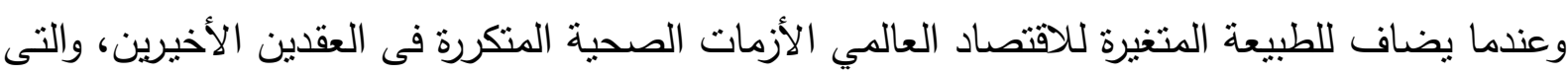
نجمت عن تفشي الأوبئة مثل: سـارس، انفلونزا الخنازير ...، وانتهاءً بفيروس كورونـا ومـا أحدثه من لن صـدمات عالميـة غير مسـوقة لكافـة قطاعـات النشـاط الانسـاني، تبـدوا الحاجـة ماسـة لتبنـي النهج الاستراتيجي المعروف بالرشاقة الاستراتيجية بأدواتها وآلياتها بما يعمق من قدرة مؤسسات التعليم من استشعار التحولات والمرونة فى التكيف معها بما يحافظ على فعاليتها التتظيمية والمجتمعية. ترى مارينـاكي Marinaki(2020) أنّ جائحسة كورونـا فرضت على المؤسسات التركيز على الرشاقة فى مواجهة احتياجات العاملين، وتوقعات العملاء، وحالة عدم اليقين السائدة، إنّ رشاقة العمل

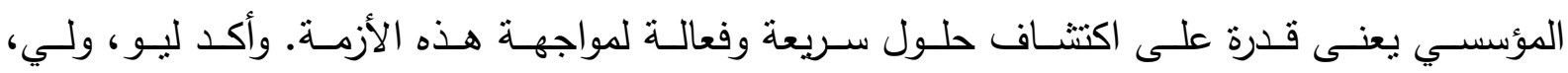
ولي Liu; Lee \& Lee (2020) على أهمية المرونة والرشاقة الاستراتيجية وريادة الأعمال فى سياق مكافحة كورونا، لأنّا فى حاجة للمرونة وتطوير استراتيجيات التأقلم الفعالة، والجهد الجماعي فى أوقات الأزمات والصدمات غير المسبوقة.

ويشبر سنوتزيل (2020) Stoetzel إلى أنّ الوقت قد حان مع وجود فيروس كورونا التاجي، للتفكير فى قدرة المؤسسات على أن تكون رشيقة استراتيجيا، وبرغم أنّ بناء القدرات والهياكل والثقافة 
لتكون رشيقا استراتيجيًا ليس بالأمرر الهين فى عالم اليوم، ولكنه أصبح ضرورة وجود للمؤسسات لتكون قادرة على الحفاظ على أو التقاط أكبر قدر من الفرص بقدر الإمكان. وتؤكد دوتي Doty Do20) أنه إذا كانت أحاديث القادة فى الماضي نظرية ومجردة عن الحاجة الكبيرة للرشاقة، وما يتعلق بها من قدرات نتيجة تزايد التقلبات، وعدم اليقين ، والتعقيد ، والغموض، فإنها الآن وفى سياق الفيروس التاجي الجديد وتردداته الاقتصادية والاجتماعية والثخصية والسياسية، لابد وأن تترجم إلى اجراءات عمل على أرض كل

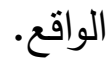

إنّ بيئـات عمل الجامعـات فى القرن الحـادي والعشـرين عمومـا ومـع تداعيات فيروس كورونـا خصوصا تقتضي توظيف الرشاقة الاستراتيجية كصيغة إدارية وتتظيمية يمكنها زيادة قدرة الجامعات على الاستجابة والتكيف بسرعة وفعالية مـع التغيرات غير المتوقعة فى بيئة عملها، بما يجعلها دائما ملبية لاحتباجات المستفيدين ومستشعرة لما قد يترتب على المسارات غير المحدة التى يمكن أن تأخذها جائحة

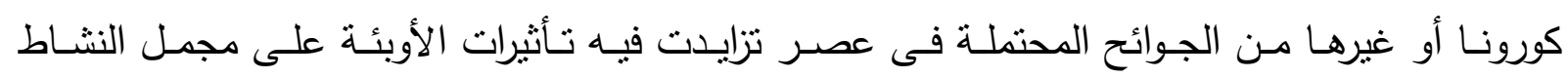
الإنساني.

وعليه تحدد هدف الورقة البحثيـة الحالية فى الكثف عن الدور الذى يمكن أن بسهم بـه تبنى الرشاقة الاستراتيجية كآلية إدارية وتتظيمية فى زيادة قدرة الجامعات المصرية على التكيف مع تداعيات فيروس كورونـا واقتتـاص الفرص المحتملة بما يعزز من استجابتها لمطالب المستقبدين المتغيرة، وبما يحفظ لها استدامة التنافسية. وتحقيقا لهدف الورقة البحثية، تتاولت مفهوم الرشاقة الاستراتيجية، وأهميتها، وأبعادها، وامكاناتها فى تعزيز قدرة الجامعات على مواجهة تداعيات فيروس كورونا وما أحدثثه من حالة من الغموض والتعقيد وما فرضته من ضرورة التغيير فى استراتيجيات العمل الجامعي على كافة الأصعدة. 